\title{
Brain Spectrin(240/235) and Brain Spectrin(240/235E): Differential Expression During Mouse Brain Development
}

\author{
Beat M. Riederer, ${ }^{1}$ lan S. Zagon, ${ }^{2}$ and Steven R. Goodman ${ }^{1}$ \\ Departments of ${ }^{1}$ Physiology and ${ }^{2}$ Anatomy, Cell and Molecular Biology Center, The Milton S. Hershey Medical Center, \\ The Pennsylvania State University, Hershey, Pennsylvania 17033
}

\begin{abstract}
Mouse brain contains at least 2 distinct spectrin subtypes: brain spectrin(240/235) and brain spectrin(240/235E) (Riederer et al., 1986). In this study, we demonstrate that these subtypes are differentially expressed during mouse brain development. Brain spectrin(240/235) can be detected in fetal tissue and increases 2-fold during brain development. This subtype is enriched in the cortical cytoplasm of germinative neural cells and is also found in fibers resembling axons as early as fetal life. Brain spectrin(240/235E), which is specifically detected with antibodies to red blood cell spectrin, is below the limits of detection in fetal and neonatal brain but rapidly increases in concentration during the second postnatal week. Brain spectrin(240/235E) is confined to the cell body and dendrites of differentiating neurons and to glial cells but is not expressed in mitotic cells. This subtype is most prominent in granule cells of the cerebellum and dentate gyrus in the hippocampus.
\end{abstract}

Spectrin is a major component of the cytoplasmic surfacc of the red blood cell $(\mathrm{rbc})$ plasma membrane. Spectrin-related molecules are also present in many nonerythroid tissues and cells (Goodman et al., 1981; Bennett et al., 1982; Burridge et al., 1982; Glenney et al., 1982; Repasky et al., 1982). Brain spectrin is a tetramer that is composed of two 240 and two $235 \mathrm{kDa}$ subunits and forms a dense cytoskeletal meshwork that may be linked by brain ankyrin to the membranes of neural cells (for review, see Goodman and Zagon, 1984, 1986; Bennett, 1985; Goodman et al., 1986a). Mammalian brain contains 2 spectrin subtypes: brain spectrin(240/235) and brain spectrin(240/235E) (Riederer et al., 1986). Both subtypes consist of 2 distinct subunits of 240 and $235 \mathrm{kDa}$. They can be distinguished by specific antibodies raised either against native mouse brain spectrin from synaptic membranes or native rbc spectrin (Goodman et al., 1986a; Riederer et al., 1986). The first antibody reacts predominantly with the $240 \mathrm{kDa}$ subunit of brain spectrin(240/235), which is found in the axonal compartments of neuronal cells. The second antibody against rbc spectrin reacts primarily with the $235 \mathrm{kDa}$ subunit of brain spectrin(240/235E), which is primarily located in dendrites and the soma of neural cells. Immunoelectron microscopic study has demonstrated that these 2

Received June 3, 1986; revised Sept. 2, 1986; accepted Sept. 13, 1986.

This work was supported in part by National Institutes of Health Grants NS19357 and HL-26059 to S.R.G. and Grant NS-221246 to I.S.Z. and S.R.G. S.R.G. is an Established Investigator of the American Heart Association. We thank Sue M. Ditty for technical assistance and David Sitler for photographic assistance.

Correspondence should be addressed to Dr. Steven R. Goodman at the above address.

Copyright (c) 1987 Society for Neuroscience $0270-6474 / 87 / 030864-11 \$ 02.00 / 0$ spectrin subtypes are discretely localized, with brain spec$\operatorname{trin}(240 / 235)$ and spectrin(240/235E) found in pre- and postsynaptic structurcs, respectivcly (Zagon ct al., 1986). In addition, this study revealed that the spectrin subtypes are not exclusively located at the cell plasma membrane, but are also associated with microtubules and neurofilaments and with membranes of organelles. It is believed that the function of spectrin subtypes might be more diversified and complex in neurons than in the highly specialized erythrocytes.

Chicken brain contains 2 spectrin subtypes [chicken brain $\operatorname{spectrin}(240 / 235)$ and spectrin(240/230) or (240/220)] (Lazarides and Nelson, 1983a), which exhibit differential expression during chicken brain development (Lazarides and Nelson, 1983b). No data are available on the developmental regulation of mammalian brain spectrin subtype expression. In this study, we demonstrate the appearance of brain spectrin subtypes during the development of mice. The subtypes differ in their initiation of expression and intracellular distribution during neuroontogeny.

\section{Materials and Methods}

\section{Isolation of spectrins}

Mouse brain spectrin(240/235) from synaptic plasma membranes and mouse rbc spectrin from erythrocytes were isolated as previously described (Riederer et al., 1986).

\section{Immunobiochemistry}

Antibody production. Antibodies were raised in rabbits against the native brain and rbc spectrin (Riederer et al., 1986). The immunoglobulins were isolated on a DEAE Aff-Gel Blue column (Bio-Rad); the antiserum was dialyzed against $20 \mathrm{~mm}$ Tris- $\mathrm{HCl}(\mathrm{pH} 8.0) / 28 \mathrm{~mm} \mathrm{NaCl}$ and applied to the column. Immunoglobulins were eluted in the void volume with the same buffer. Other serum proteins were eluted with $1.4 \mathrm{M} \mathrm{NaCl}$ in Tris buffer. The immunoglobulins were depleted of cross-reactive antibodies on rbc- and brain spectrin-affinity columns, respectively (Riederer et al., 1986). Antiserum against mouse hemoglobin is commercially available (Cappel).

Quantitative immunodot assay. Defined amounts of spectrin (in the ng range) or $1 \mu \mathrm{g}$ of brain homogenate were spotted onto nitrocellulose filters and incubated with antibodies and ${ }^{125} \mathrm{I}$-Protein $\mathrm{A}$ as described elsewhere (Riederer et al., 1986). The assay was slightly modified, in that BSA was replaced by $5 \%$ nonfat dried milk as a blocking agent. Each determination was performed in triplicate and assayed for radioactivity in a Packard 500 gamma counter. Nonspecific binding was determined by using preimmune IgG or using squares without dotted proteins. These values were subtracted from values with specific antibodies to obtain the specific binding.

Preparation of the brain tissue samples. Animals obtained at prenatal day 15 and 18, birth (day 0 ), and postnatal days $1,3,6,8,10,13,15$, $18,21,30$, and 60 (adult) were prepared as described previously (Riederer et al., 1986), and brains were weighed and tissues were homogenized 


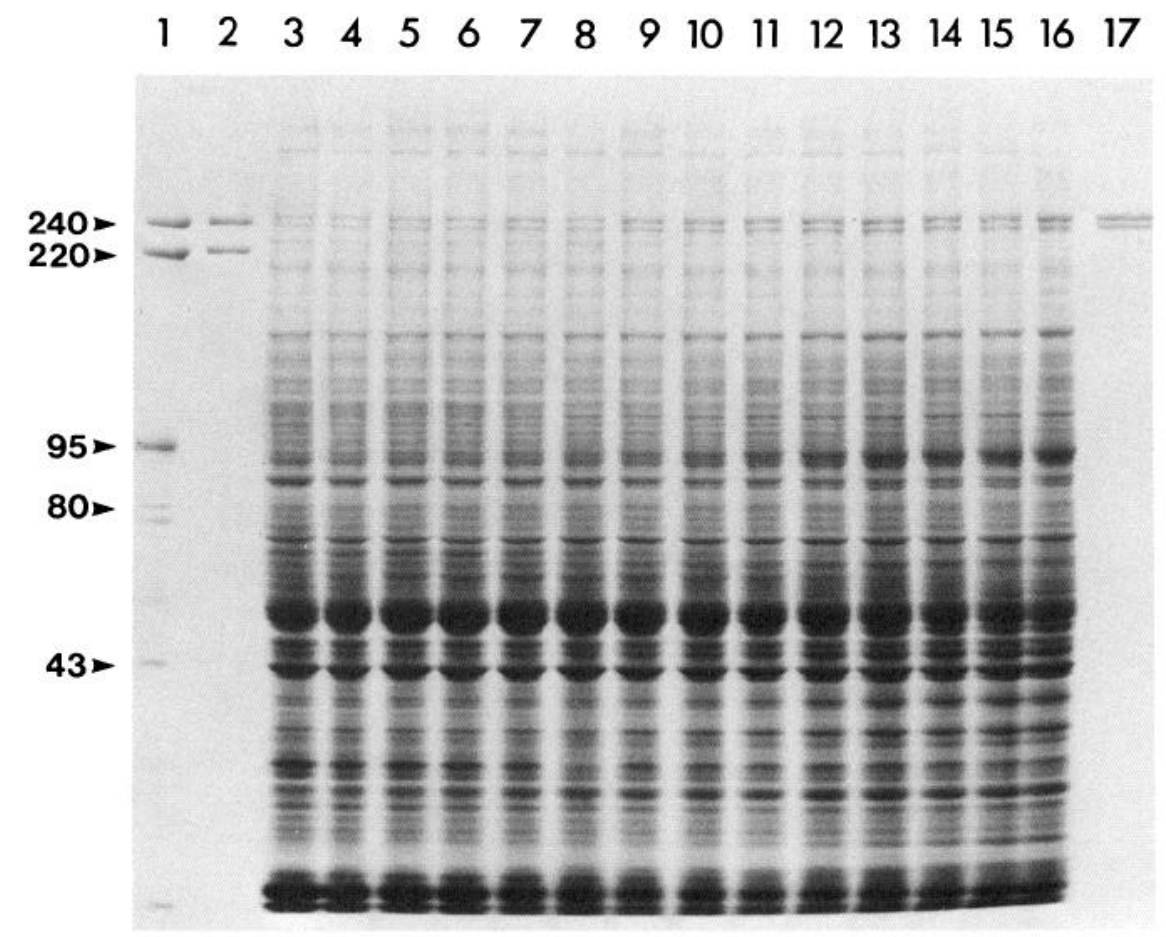

B

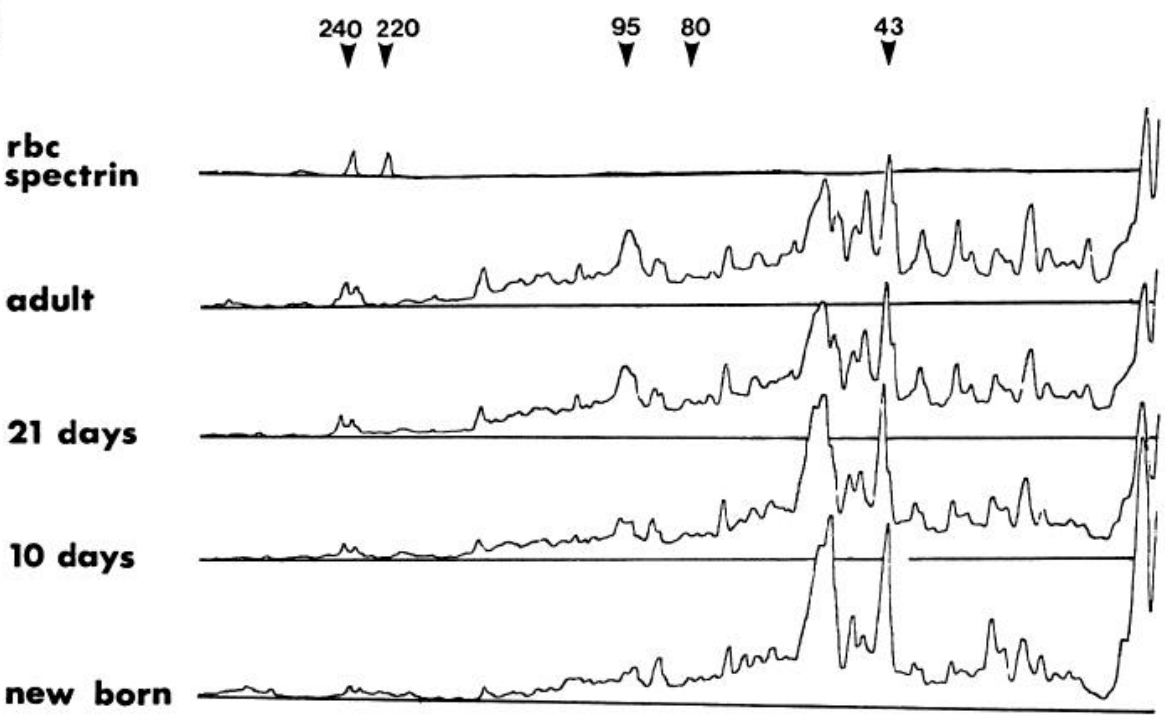

\section{brain spectrin}

Figure 1. Spectrin content of developing mouse brain. Mouse brain protein samples were separated by $5-15 \%$ polyacrylamide gradient SDS slab gel electrophoresis and stained with Coomassie blue $(A)$; some of those developmental stages were scanned densitometrically $(B)$. Protein samples in $A$ represent: 1 , rbc ghost $(2.4 \mu \mathrm{g}) ; 2$, rbc spectrin $(0.63 \mu \mathrm{g}) ; 3-16,40 \mu \mathrm{g}$ of brain homogenate of embryonal days 15 and 18 , newborn, postnatal days $1,3,6,8$, $10,13,15,18,21,30$, and adult animals; 17 , purified brain spectrin(240/ 235) $(0.6 \mu \mathrm{g})$. at $100 \mathrm{mg}$ brain/ $1 \mathrm{ml}$ of low-ionic-strength buffer ( $0.1 \mathrm{~mm}$ EGTA, 0.25 $\mathrm{mm}$ dithiothreitol, and $0.2 \mathrm{~mm}$ diisopropylfluorophosphate, $\mathrm{pH} \mathrm{7.4)} \mathrm{at}$ $0^{\circ} \mathrm{C}$. The protein amount was measured by a modified Lowry assay (1951) by dissolving the protein sample in 5\% SDS. BSA was used as a standard. The brain homogenate protein was brought to $2 \mathrm{mg} / \mathrm{ml}$ in low-ionic-strength buffer for the quantitative immunodot assay and spotted immediately or prepared for SDS-PAGE.

Electrophoresis and immunoblots. Protein samples were separated on 5-15\% polyacrylamide-SDS slab gels (Laemmli, 1970). Quantitation of Coomassie blue-stained bands was carried out by densitometry on a soft laser scanner (Zeineh, LKB). Proteins were transferred to nitrocel- lulose filter (Millipore) as previously reported (Riederer et al., 1986). Blots were washed with TBS ( $50 \mathrm{~mm}$ Tris- $\mathrm{HCl}, \mathrm{pH} 7.4,120 \mathrm{~mm} \mathrm{NaCl}$ ) blocked with $5 \%$ nonfat dried milk, $0.1 \%$ Triton X-100 in TBS for 60 min, and reacted with the antibody overnight. After 4 washes with $0.1 \%$ Triton X-100 in TBS, the blots were incubated in blocking solution together with $0.1 \mu \mathrm{Ci} / \mathrm{ml}^{125} \mathrm{I}$-Protein $\mathrm{A}$ for $2 \mathrm{hr}$. The filters were washed extensively with TBS until no radioactivity was detected in the wash solution. Autoradiography was performed using Kodak X-Omat XAR5 film exposed at $-20^{\circ} \mathrm{C}$ for $24 \mathrm{hr}$ and longer. The spectrin subunits were also cut out and measured for radioactivity in a gamma counter (Packard). 

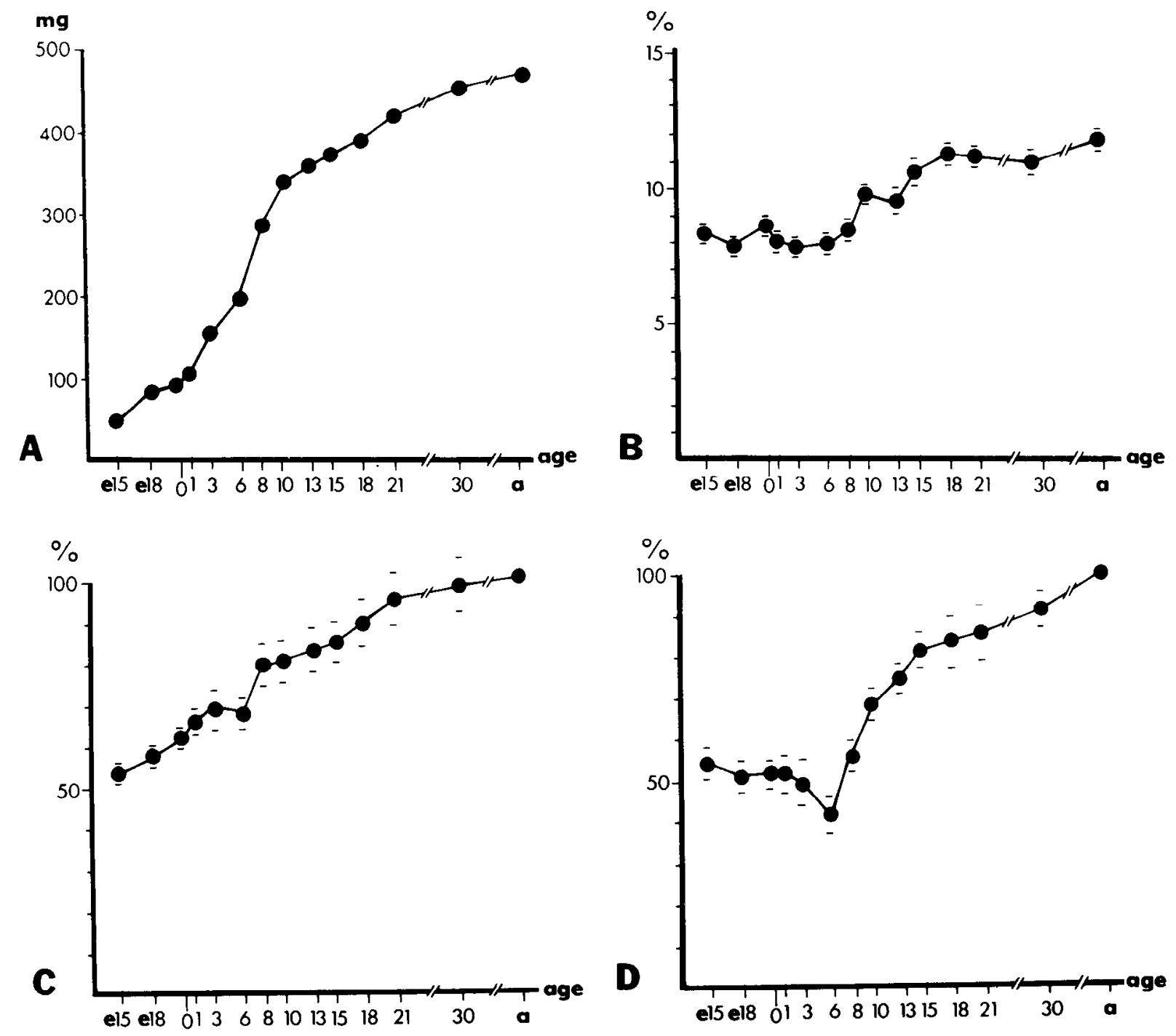

Figure 2. Quantitation of spectrin subtypes in developing brain by an immunodot assay. Developmentally regulated changes of mouse brain tissue between embryonal day 15 (el5), 18 (el8), newborn (0), days 1-30, and adult stage. $A$, Gradual increase of frozen brain weights (in mg). $B$, Total brain protein per frozen brain tissue (in \%). $C$ and $D$, Quantitative immunodot assay. The presence of brain spectrin(240/235) is determined in $1 \mu \mathrm{g}$ brain homogenate dots by using an antibody against brain spectrin(240/235) (C). The rbc-related brain spectrin(240/235E) was measured with an antibody against $\mathrm{rbc}$ spectrin $(D)$. The $\mathrm{cpm}$ value of the specific binding of antibody-125I-protein $A$ to the different developmental stages on the dots was expressed as the percentage of the value for adult brains. Nonspecific binding of ${ }^{125} I$-protein $A$ to nitrocellulose squares with specific and preimmune serum was between $60-80 \mathrm{cpm}$. The values of specific binding were between $500-2000 \mathrm{cpm}$. Antibody dilution was $20 \mu \mathrm{g} \mathrm{IgG/ml}$.

\section{Immunocytochemistry}

On prenatal days 15 and 18 , birth, and postnatal days $3,6,10,15,21$, 30 , and adult (60-90 d), at least 3 animals were randomly selected from 2 or more litters for immunocytochemical examination; all litters were culled to 8 pups/mother to control for differences in development due to litter size. Mice were anesthetized, perfused intracardially, and processed for immunocytochemistry according to previously published procedures (Zagon et al., 1984). Sections of $20 \mu \mathrm{m}$, obtained on a Slee cryostat, were stained with anti-brain spectrin $(240 / 235)$ or anti-rbc spectrin, and rhodamine-conjugated goat anti-rabbit IgG; control specimens stained with either preimmune IgG, brain spectrin absorbed anti-brain spectrin(240/235) IgG, or anti-rbc spectrin IgG were included. Sections stained with gallocyanin were used for gencral oricntation and morphology.

In order to obtain a relative comparison of staining patterns and concentration, the following procedure was utilized. A time point during ontogeny in which one-half of the maximal increase in concentration of each spectrin subtype was noted. In the case of both subtypes, this time point was postnatal day 10 (see Figs. 1 and 3). Using the interna granule layer as a standard, at least 10 independent measures (obtained from at least 3 different sections) of exposure times were determined within a $40 \mu \mathrm{m}$ diameter circular field with an Olympus automatic camera equipped with a silicon blue cell and digital readout. The average of these exposure and printing times is given in the figure legends.

\section{Results}

Spectrin quantitation in developing mouse brain

Mammalian brain spectrin contains a comixture of 2 distinct subtypes: spectrin(240/235) and spectrin(240/235E) (Riederer et al., 1986). As shown in Figure 1, the content of total brain spectrin increases constantly during mouse brain development. Spectrin can be visualized on a Coomassie blue-stained gel of a brain homogenate of a $15 \mathrm{~d}$ mouse fetus (Fig. $1 \mathrm{~A}$ ). Gel scanning densitometry and peak integration indicates that total brain spectrin comprises $1.30 \%$ of the total protein of newborn mouse brain and increases to a value of $2.76 \%$ of the protein of adult mouse brain (Fig. 1B).

In order to determine the expression of the individual brain 

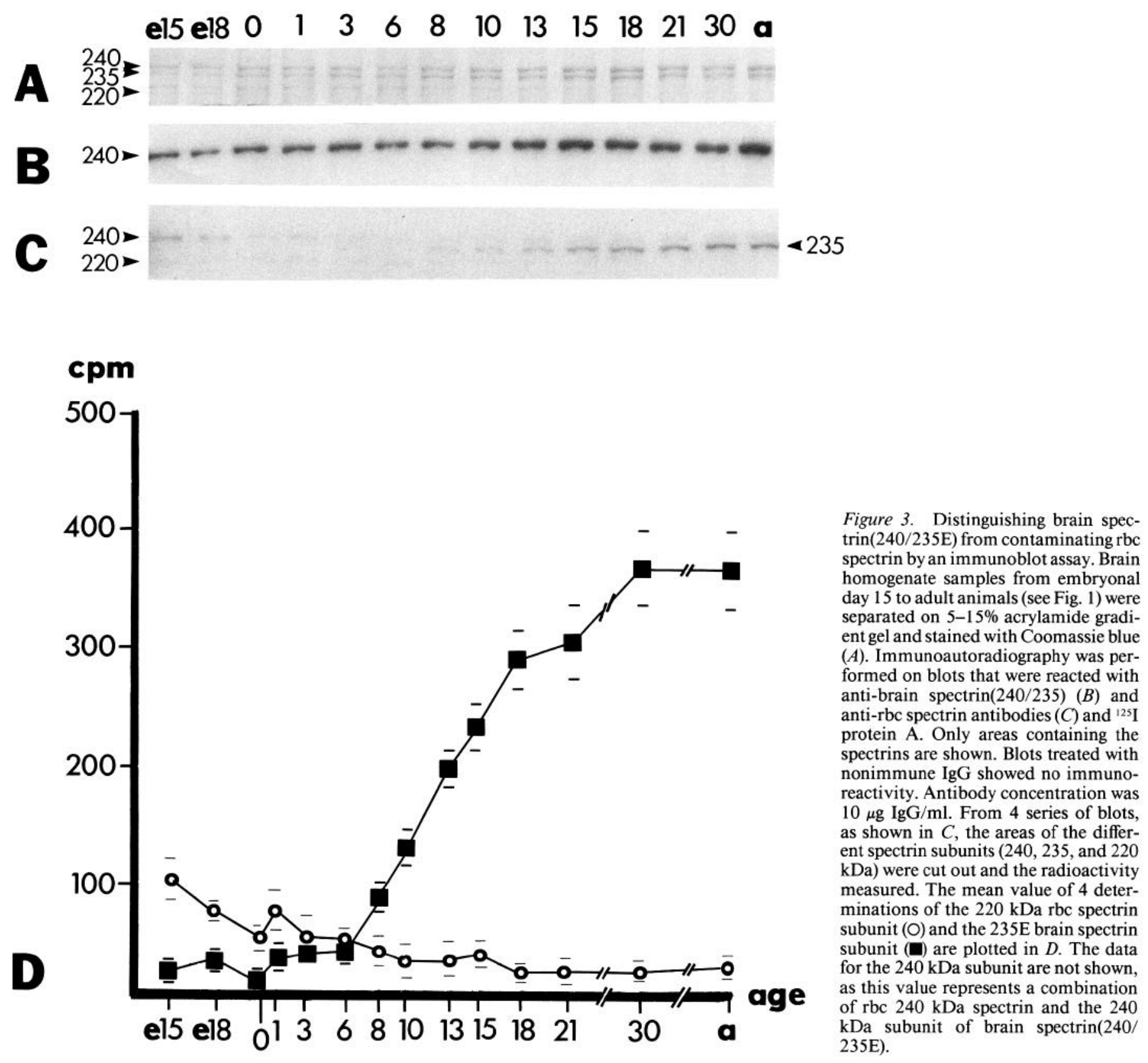

spectrin subtypes during mouse brain development, an antibody against mouse brain spectrin(240/235) and an antibody against mouse rbc spectrin that recognizes brain spectrin(240/235E) exclusively (Riederer et al., 1986) were utilized in a quantitative immunodot assay (Fig. 2). As shown in Figure $2 A$, brain weight increases 10 -fold between prenatal day 15 and adulthood. Total brain protein represents $\sim 8 \%$ of the brain weight in the late prenatal period and during the first postnatal week. During the following 2 weeks the protein amount/brain weight increases gradually to the adult value of $12 \%$ (Fig. $2 B$ ). Quantitative dot assay for brain spectrin(240/235) demonstrates that this subtype increases steadily during mouse brain development (Fig. 2C). The absolute amount of brain $\operatorname{spectrin}(240 / 235)$ at embryonal day 15 was $12.0 \mathrm{ng} / \mu \mathrm{g}$ of brain protein and increased during development to a final value of $23.6 \mathrm{ng} / \mu \mathrm{g}$ brain protein in adults. For these determinations, purified synaptoplasmic brain spectrin(240/235) was used for the standard curve (Riederer et al., 1986). Brain spectrin(240/235E) detected with an rbc spectrin antibody appeared to decrease slightly from embryonal day 15 to postnatal day 6 , increased rapidly from postnatal day 6 through day 15 , and increased more gradually from day 15 to adulthood (Fig. 2D). Of course, only relative concentrations of brain spectrin $(240 / 235 \mathrm{E})$ can be calculated, as purified brain spectrin(240/235E) was unavailable to serve as a standard.

We believed that the small decrease in the amount of rbcrelated spectrin seen on the immunodot assay from brain homogenates of animals of prenatal day 15 through postnatal day 6 mouse brain homogenates (Fig. 2D) could be due to contamination with rbc spectrin in the early developmental stages when mice are often more difficult to perfuse. To explore this further, we ran an immunoblot assay on the brain homogenates where staining of the $235 \mathrm{kDa}$ subunit of brain spectrin(240/235E) by 

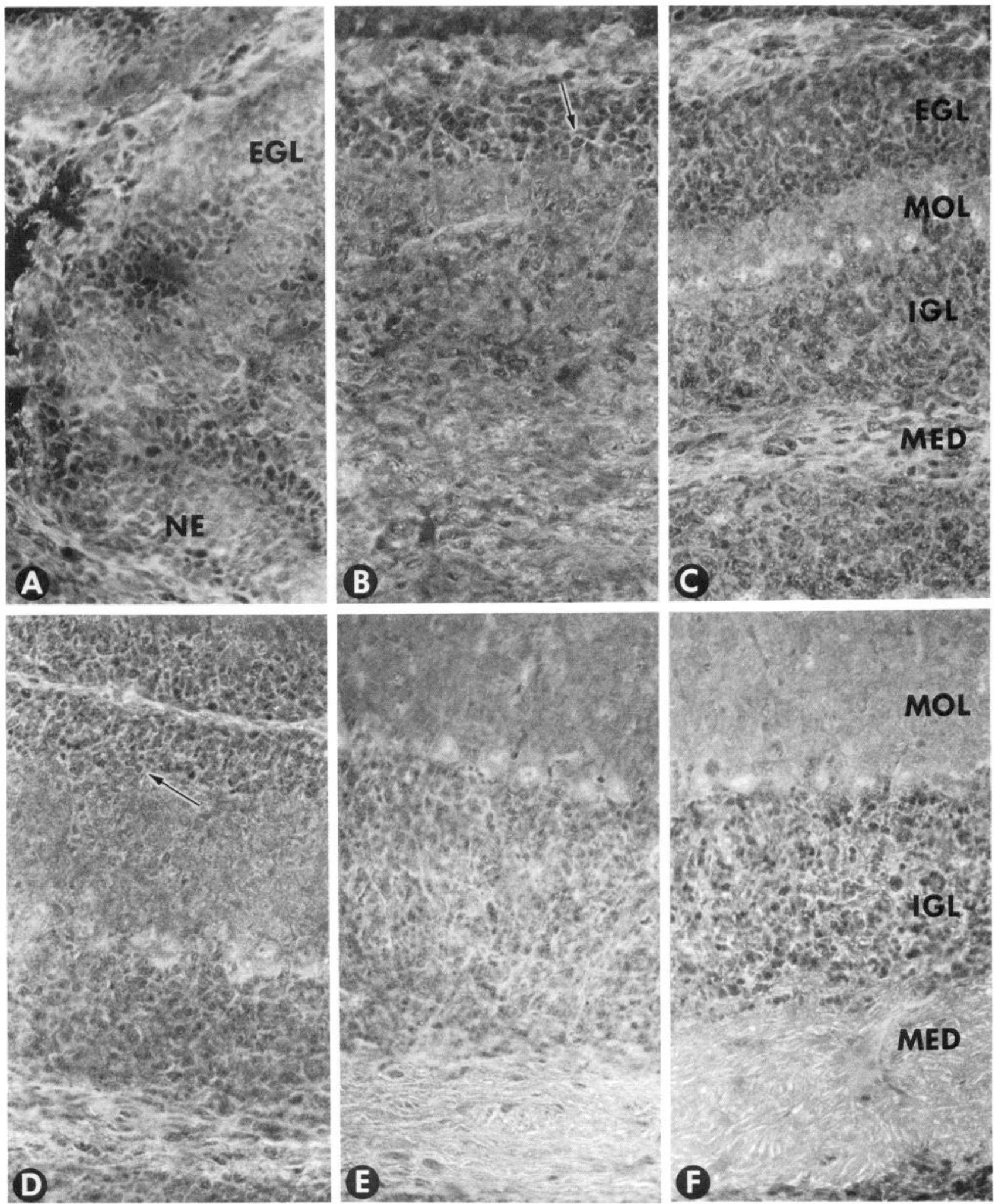

Figure 4. Brain spectrin(240/235) localization in sagittal sections during cerebellum development. The cerebellar cortex of animals sampled at fetal days $15(A)$ and $18(B)$, at postnatal days $6(C), 10(D), 30(E)$, and in adulthood $(F)$. Exposure time for all figures, 29 sec, was based on the readings from the internal granule layer $(I G L)$ of 10 -d-old animals; printing time averaged $20 \mathrm{sec}$. Note the generally high level of immunoreactivity in the cerebellum as early as fetal day 15. A brightly fluorescent "ring" of cortical cytoplasm (arrow) was recorded in both neuroepithelial (NE) and external germinal cells $(E G L)(A-D)$. Neural cells in the IGL generally had little immunofluorescence, in contrast to EGL cells $(D)$. In the medullary layer $(M E D)$, cells tentatively identified as glia also exhibited immunoreactivity of the cortical cytoplasm $(C, D)$. Other elements in the MED, often resembling fibers, were intensely stained in younger animals $(C, D)$; after day 15 , these elements were noted to be fibers $(E, F)$ that also extended into IGL. Magnification of all micrographs, $\times 325$. 

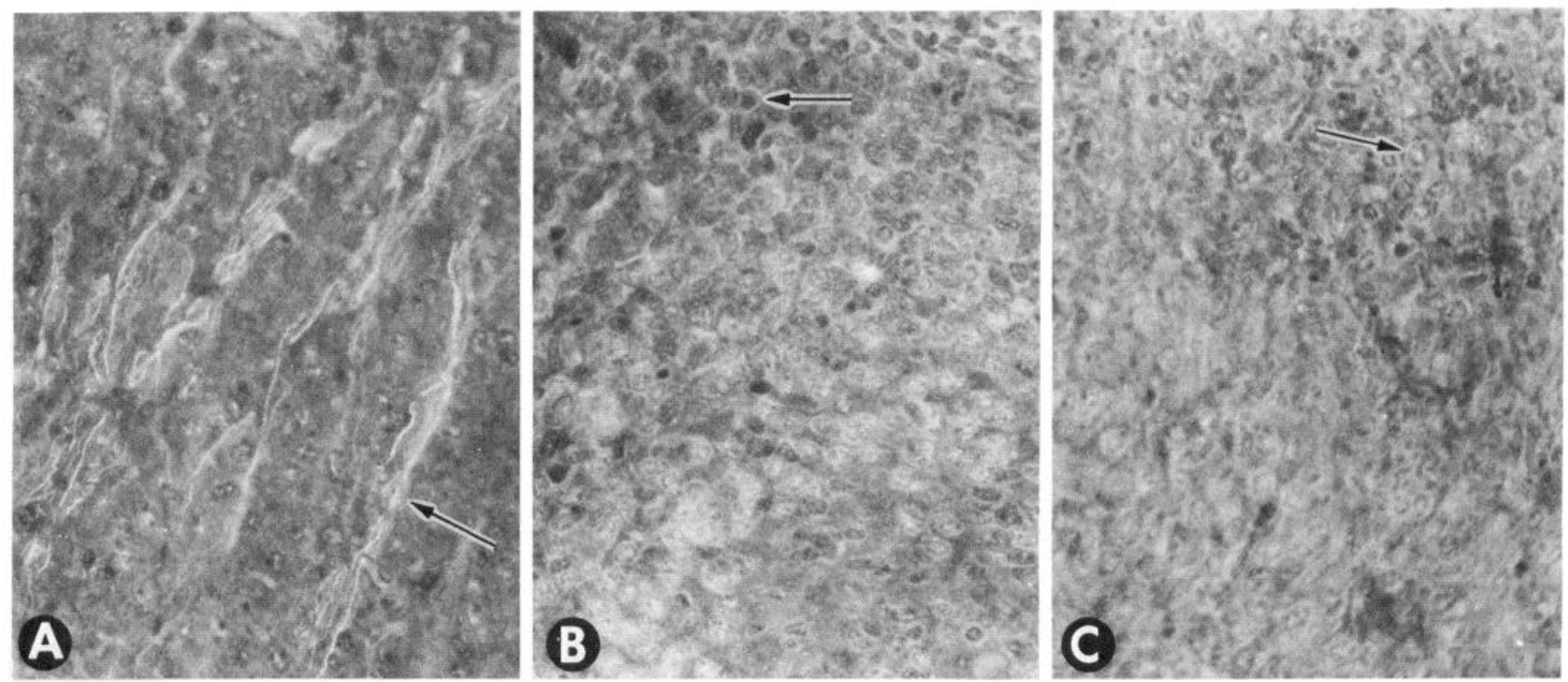

Figure 5. Brain spectrin(240/235) detection in brain tissue of newborn mice. Even as early as birth, numerous fibers intensely stained with antibrain spectrin IgG could be observed in the brain stem $(A)$ and other areas of the mouse brain. Cells in the dentate gyrus $(B)$ and cerebral cortex $(C)$ of the newborn mouse exhibited immunoreactivity of their cortical cytoplasm (arrow). Magnification of all micrographs $\times 325$. Exposure and printing time as in Figure 4.

the rbc spectrin antibody could be clearly distinguished from staining of the $220 \mathrm{kDa} \beta$ subunit from contaminating rbc spectrin (Fig. $3 C$ ). As shown in Figure $3 C$, on staining brain homogenate protein (separated by SDS-PAGE) with rbc spectrin antibody followed by ${ }^{125} \mathrm{I}$-protein A, little staining of the $235 \mathrm{E}$ subunit was observed from embryonal day 15 through postnatal day 6 . A rapid increase in the staining of the $235 \mathrm{E}$ subunit was observed from postnatal day 6 through adulthood. Conversely, the $220 \mathrm{kDa}, \beta$ rbc spectrin subunit was clearly stained on prenatal day 15 but decreased to background levels by postnatal day 10 . These findings, quantitated by cutting out the ${ }^{125}$ I-labeled bands and counting radioactivity (Fig. $3 D$ ), indicated clearly that the protein detected with rbc spectrin antibody, which diminishes during the earliest stages of mouse brain development (Fig. 2D), is due to contaminating rbc spectrin. Brain spec$\operatorname{trin}(240 / 235 \mathrm{E})$ is present at a low concentration from prenatal day 15 through postnatal day 6 , after which it rapidly increases through the remainder of neuro-ontogeny (Fig. $3 D$ ). Similar conclusions were reached using an anti-mouse hemoglobin antibody to quantitate rbc contamination by a quantitative immunodot assay (data not shown). As shown in Figure $3 B$, unlike brain spectrin(240/235E), brain spectrin $(240 / 235)$ is present in substantial quantities at embryonal day 15 , and its concentration increases constantly during brain development.

\section{Immunocytochemistry}

Immunofluorescent localization of brain spectrin(240/235). Examination of sagittal and coronal sections of developing mouse brain stained with anti-brain spectrin(240/235) IgG revealed a pattern of immunoreactivity dependent on age and brain location. Examination of the fetal brain revealed that germinal cells emanating from the ventricle were stained with this antibody (Fig. $4 A$ ). The disposition of staining was such that the cortical cytoplasm was immunofluorescent, but cell nuclei were negative. Secondary germinative matrices also demonstrated immunoreactivity. Thus, in the cerebellar cortex of fetal day 15
(Fig. 4A), for example, germinal cells located in the neuroepithelium and the external germinal layer exhibited this characteristic staining pattern. Cellular elements that migrated from the neuroepithelium (e.g., neuroblasts) continued to demonstrate some immunofluorescence for a short time after birth. Examples of this occurred in the hippocampal formation (Fig. $5 B$ ) and cerebral cortex (Fig. 5C). Also apparent at the time of birth was the extremely intense staining of fibrous-like elements, particularly in the brain stem (Fig. $5 A$ ). These fibers were of varying diameters and lengths, and were often found in aggregates. Immunofluorescent fibers became numerous during the course of ontogeny and were found throughout the brain (e.g., cerebral cortex and brain stem).

The ontogeny of brain spectrin(240/235) antigen was intensively studied in the cerebellum. The well-known development of this region, along with its discrete architectural boundaries, has made this a particularly good area for understanding the mechanisms of brain development. The ontogeny of brain spec$\operatorname{trin}(240 / 235)$ in the cerebellum is illustrated in Figure 4, $A-F$. As mentioned earlier, the external germinal cells exhibited an immunofluorescence of the cortical cytoplasm, but not of cell nuclei (Fig. 4, $A-D$ ). The molecular layer was, to some degree, immunofluorescent even in young animals (Fig. 4, $C, D$ ). Purkinje neurons were also immunoreactive to a limited extent, being particularly visible from postnatal day 10 onward (Fig. 4, $D-F)$. The internal granule layer exhibited little immunofluorescence until the end of the second postnatal week (compare Fig. $4, D, E$ ). At this time, brightly staining fibers from the medullary layer were observed to be coursing through the internal granule layer (Fig. 4, E, F). In addition, "pools" of immunofluorescence often were recorded between granule cells (Fig. 4, E, F). The medullary layer was distinctly immunofluorescent from the first postnatal week onward. Prior to postnatal day 15 , the medullary layer was composed of cells with dark nuclei but stained cytoplasm, with amorphous-like immunoreactive material between cells. During the third postnatal week, 

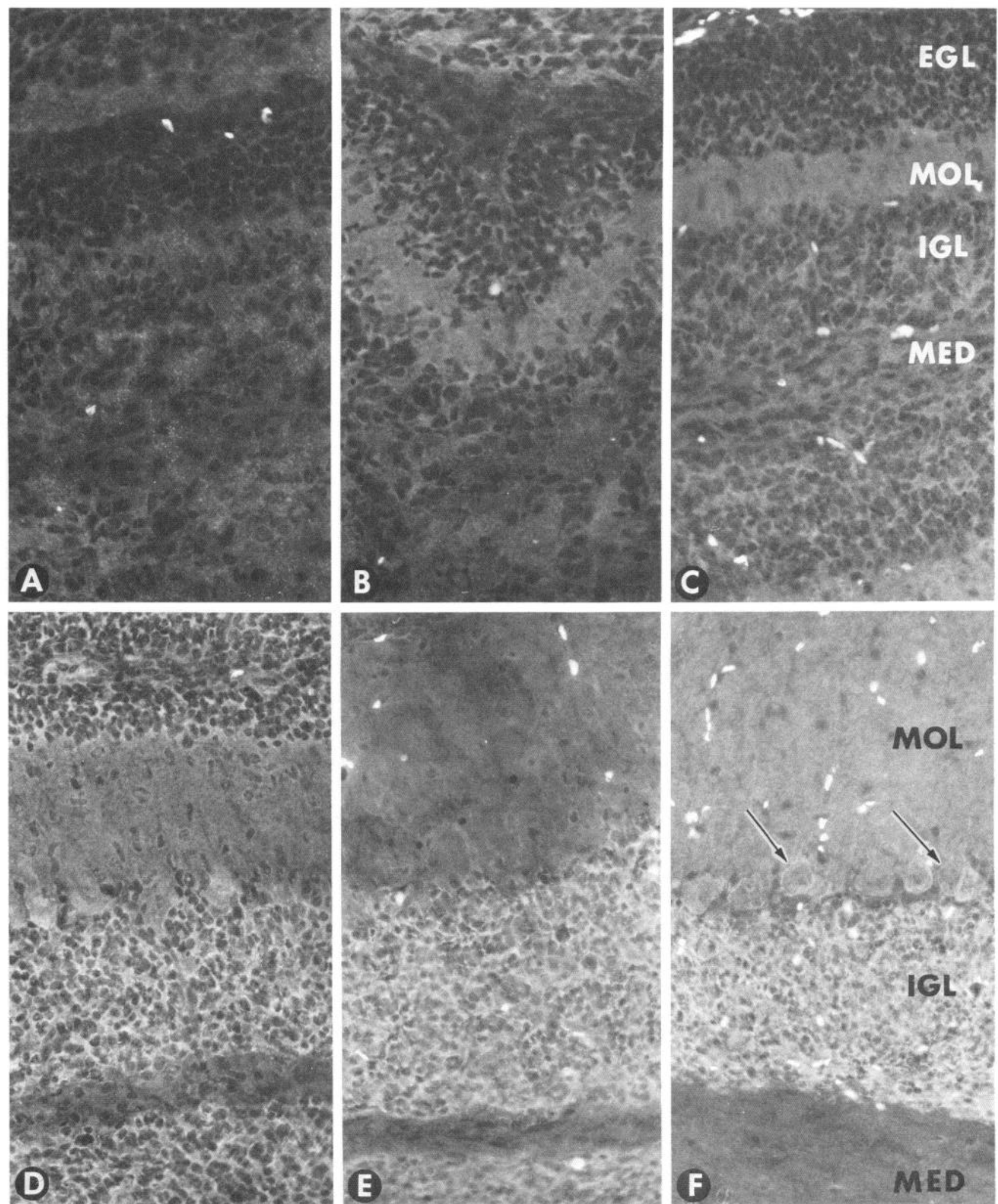

Figure 6. Brain spectrin(240/235E) localization in sagittal section of cerebellum during development. This series of photomicrographs of the cerebellar cortex from mice sampled at fetal day $18(A)$, birth $(B)$, and postnatal days $6(C), 10(D), 21(E)$, and $30(F)$ demonstrates the ontogeny of brain spectrin(240/235E). All specimens were photographed at $39 \mathrm{sec}$, and printing time averaged 31 sec. These times were established by monitoring the internal granule layer $(I G L)$ of a 10 -d-old animal $(D)$. The external germinal layer $(E G L)$ exhibited little immunoreactivity $(A-D)$ In 10-d-old animals $(D)$ and older $(E, F)$, cellular elements in the IGL displayed a characteristic staining on the cortical cytoplasm. Purkinje neurons (arrows) were generally distinct in animals older than $10 \mathrm{~d}$. In some instances, erythrocytes remaining in tissue can be observed, and these were extremely fluorescent. Molecular layer, $M O L$; medullary layer, $M E D$. Magnification of all micrographs, $\times 325$. 

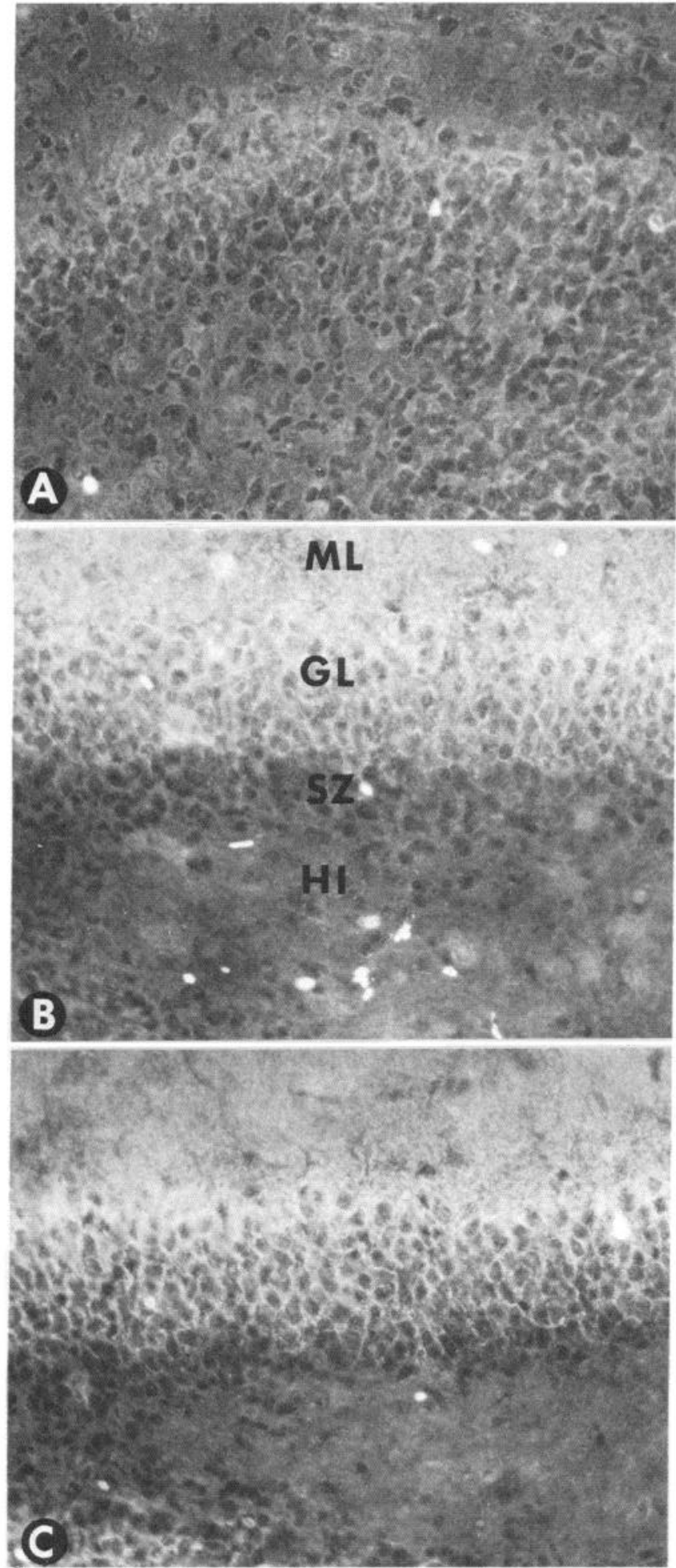

Figure 7. Brain spectrin(240/235E) during development of the granule cell in the dentate gyrus. The ectal limb of the dentate gyrus at postnatal days $3(A), 15(B)$, and $30(C)$. At day 3 , some immunofluorescent cells can be detected in the layers of cells proximal to the molecular layer $(M L)$. By day 15 , the granule layer $(G L)$ is substantial in size and composed of immunoreactive cells; subjacent to the GL, the subgranular zone $(S Z)$ contains cell types with little immunoreactivity. At day 30 , the SZ contains only 1 or 2 layers of immunofluorescent-negative cells; the SZ disappears by adulthood. HI, hilus. Magnification of all micrographs, $\times 325$. Exposure time was $39 \mathrm{sec}$; printing time averaged $31 \mathrm{sec}$.
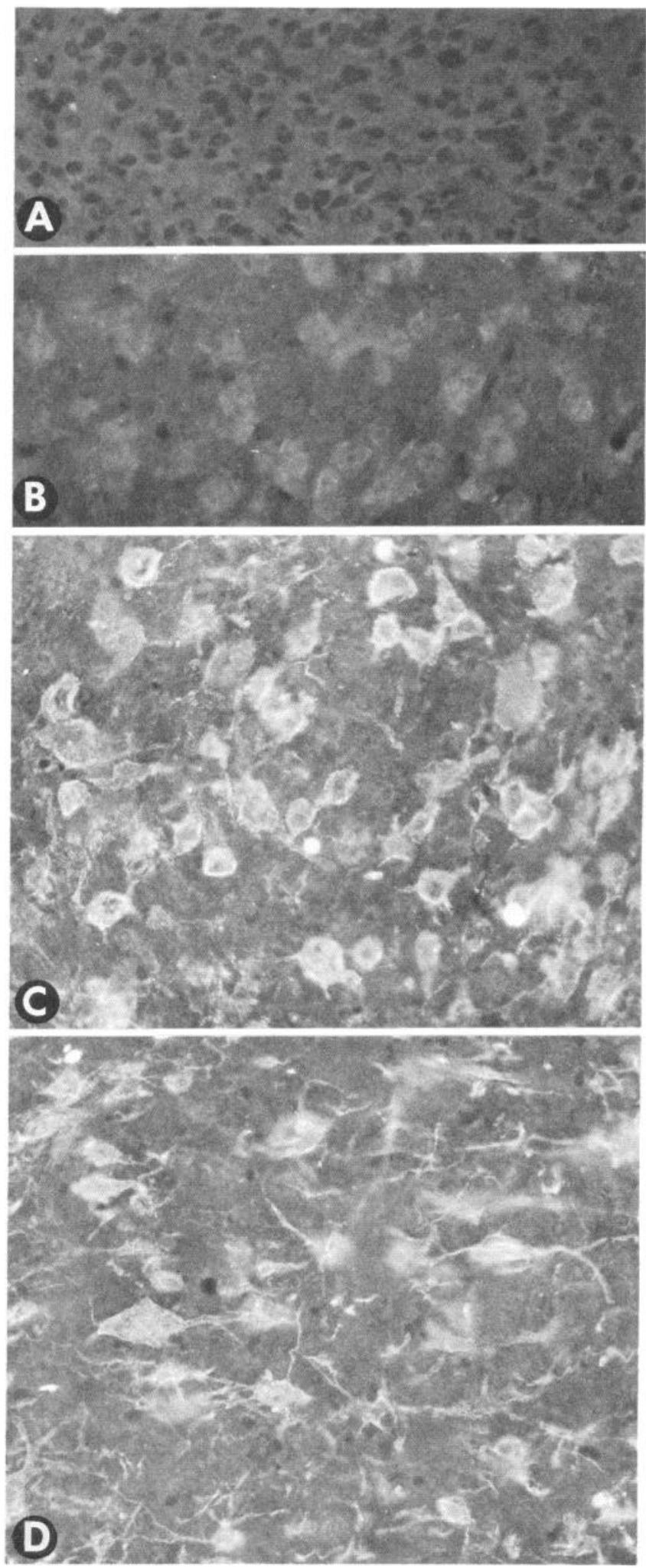

Figure 8. Brain spectrin(240/235E) expression in neurons of the medullary reticular formation. Medullary reticular formation at birth $(A)$ and postnatal days $10(B), 15(C)$, and adult $(D)$. The soma of neuronal cells can be recorded within the first postnatal week $(B)$, and small processes were observed by the end of the second week $(C)$. The complex network of cells and processes recorded in the adult $(D)$ usually occurred between postnatal day 30 and adulthood. Photomicrographs were exposed for $39 \mathrm{sec}$ and printed for an average of $31 \mathrm{sec}$. Magnification of all micrographs, $\times 325$. 

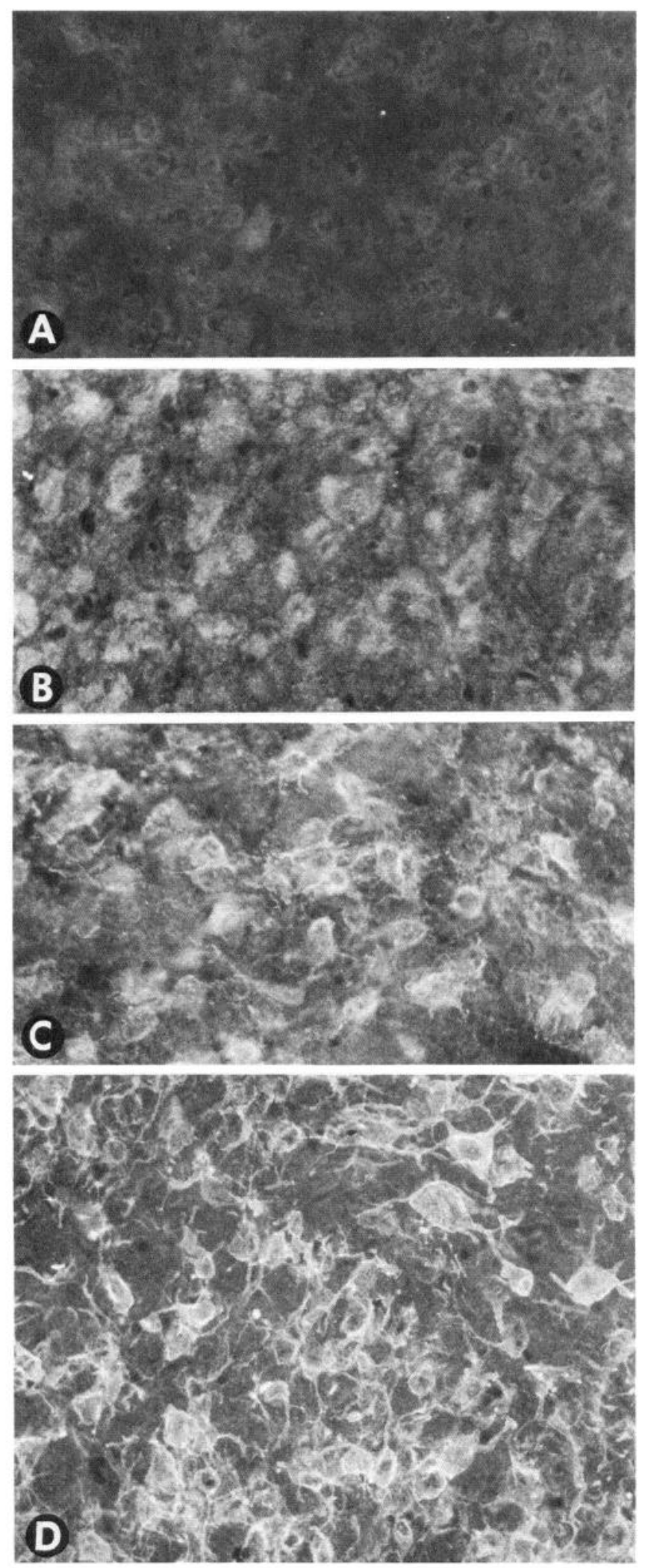

Figure 9. Brain spectrin(240/235E) in pontine nuclei. Pontine nuclei at birth $(A)$ and postnatal days $10(B), 15(C)$, and $30(D)$. Cellular elements exhibited little immunofluorescence until the second postnatal week. Immunoreactivity in the cell soma was intense by day $15(C)$, but the cells generally had short, spikelike processes that were fluorescent. Between day $30(D)$ and adulthood, an intricate pattern of immunoreactivity was established. Photomicrographs were exposed for 39 $\mathrm{sec}$ and printed for an average of $45 \mathrm{sec}$. Magnification of all micrographs, $\times 325$. this layer exhibited brightly stained, distinct fibers; cellular elements were not immunoreactive. As mentioned previously, these fibers were seen to be coursing through the internal granule layer (Fig. 4, E, F).

Immunofluorescent localization of brain spectrin(240/235E). Examination of sagittal and coronal sections of developing mouse brain stained with anti-rbc spectrin IgG revealed an immunoreactive pattern that was especially dependent on age (Figs. 69). Characterization of cerebellar ontogeny in regard to brain spectrin(240/235E) was particularly revealing. Very little staining was recorded (Fig. 6, $A, B$ ) in the cerebella of fetuses and neonates. Thus, cells in both primary (i.e., neuroepithelium) and secondary germinative matrices (e.g., external germinal layer) were unstained, as were other cerebellar regions (e.g., medullary layer). A "haze" of some immunoreactivity sometimes could be detected in the molecular layer of young animals (Fig. $6, B, C$ ); however, it should be reiterated that this was a low level of immunofluorescence. In addition, highly immunofluorescent strandlike elements located in the medullary layer often could be observed after postnatal day 6 and were especially prominent on day 15 . At day 10 (Fig. $6 \mathrm{D}$ ), internal granule cells, which were negative for immunoreactivity up to this point (see Fig. 6, $B, C$ ), exhibited bright staining of their cortical cytoplasm. Other neural cells (e.g., Purkinje neurons) also showed some immunofluorescence at this time (Fig. 6, D-F). At $30 \mathrm{~d}$, glial cells in the medullary layer showed little immunofluorescence (Fig. 6, $C-F$ ).

An extensive examination of the brain showed that brain spectrin(240/235E) antigen was negligible in fetal and neonatal mice (Figs. $8 A, 9 A$ ). In the hippocampus, the pyramidal cells demonstrated some immunofluorescence at postnatal day 3, which continued to increase in intensity at later ages. The appearance of brain spectrin $(240 / 235 \mathrm{E})$ in the dentate gyrus was related to areas of differentiation. Thus, in both the ectal (Fig. $7, A-C$ ) and endal limbs of the dentate gyrus, cells in the subgranular zone were not stained, in contrast to those cells constituting the granule layer. In the course of ontogeny, the number of rows of cells that were unstained decreased and, by day 30 , only 1 or 2 layers were apparent (Fig. 7C). All granule cells were immunofluorescent in adult animals.

In the medullary reticular formation (Fig. 8, $A-D$ ), some staining of the neural cell soma could be detected by postnatal day 10 (Fig. $8 B$ ), and small processes were observed by day 15 . However, the extensive network of cell processes emerged between days 30 and adulthood. The pontine nuclei exhibited a similar pattern of brain spectrin(240/235E) ontogeny (Fig. 9, $A$ $D$ ). In regard to other brain regions (e.g., cerebral cortex, midbrain), the appearance of brain $\operatorname{spectrin}(240 / 235 \mathrm{E})$ was consistent with the areas of the nervous system just described. In general, these areas had little fluorescence before postnatal day 10 , with the characteristics of the adult appearing during the subsequent postnatal weeks.

\section{Discussion}

Brain spectrin subtype expression during mammalian brain development

The results of this biochemical and immunohistochemical study represent the first account of the development of spectrin in the mammalian nervous system. Our data clearly demonstrate that the 2 brain spectrin subtypes examined, brain spectrin(240/235) and brain spectrin(240/235E), are differentially expressed during neuro-ontogeny. Brain spectrin(240/235) can be detected in 
very early stages of brain development, with its concentration in the fetus being $50 \%$ of that in the adult. This subtype was found in the cortical cytoplasm of germinative cells and in fibers resembling axons during fetal and neonatal stages of development. In the preweaning period, brain spectrin(240/235) was localized in axons and presynaptic areas (Riederer et al., 1986; Zagon et al., 1986). Unlike brain spectrin(240/235), brain spec$\operatorname{trin}(240 / 235 \mathrm{E})$ was not observed in brain tissues of prenatal mice. Indeed, brain spectrin $(240 / 235 \mathrm{E})$ initially appeared to be expressed by the end of the first postnatal week. In the second postnatal week, this subtype was prominently located in neuronal cell bodies and dendrites, as well as in the soma of glial cells.

The relationship of the ontogeny of brain spectrin subtypes to neuro-ontogenic processes is presently unclear. Brain spec$\operatorname{trin}(240 / 235)$ appears to be associated with cell proliferation and/or neuroblasts, since it was an integral component of all germinal cells. This subtype's localization in fibers in the fetal nervous system, perhaps in pathfinder and pioneering processes, also indicates another aspect to brain spectrin(240/235). The clearest pattern decipherable in regard to this spectrin subtype was its increasing presence in axons throughout the brain concomitant with maturation. Whether brain spectrin(240/235) "relocates" from the cytoplasm to the axon during ontogeny awaits further examination. The developmental neurobiology of brain spectrin(240/235E) did not seem to be distinctly related to any particular phase of neuro-ontogeny. This subtype was difficult to detect until the second postnatal week, despite differences in the temporal patterns of neurogenesis throughout the brain. For example in the cerebellum - an area of rigorously defined morphogenesis (Altman, 1972a, b) in which the stages of neurogenesis, synaptogenesis, and gliogenesis have been carefully described - this subtype was not detected in internal granule neurons until day 10 , indicating that brain spectrin(240/ 235E) was not directly linked to overt differentiation or synaptogenesis. The "trigger" for the onset of the initial expression of this subtype throughout the brain on day 10 can only be speculated upon at this time. For example, during the second week of life, sensorimotor systems in the rodent (Zagon and McLaughlin, 1978) reach a state of maturation that may be of importance in the expression of this spectrin subtype. The fact that brain spectrin(240/235E) is not expressed in mouse neuroblastoma cells (Goodman et al., 1986b) also may suggest that an external signal is needed to initiate brain spectrin $(240 / 235 \mathrm{E})$ synthesis.

\section{Relationship of brain spectrin subtype expression to other cytoskeletal proteins}

Unlike the brain spectrin subtypes, whose expression is maximal in 30-d-old and adult mouse brain, actin and tubulin in mouse and rat brain are maximally expressed between birth and postnatal day 5, after which there is a decline in their content (Schmitt et al., 1977). Like brain spectrin(240/235), neurofilament 145 and $68 \mathrm{kDa}$ subunits are expressed in the prenatal rat brain and then increase steadily during brain development. The $200 \mathrm{kDa}$ neurofilament subunit is not expressed until postnatal day 10 , at which time it increases rapidly to its adult levels, in a manner similar to the expression of brain spectrin(240/235F) (Shaw and Weber, 1982). However, while brain spectrin(240/235E) is found in neuronal cell bodies and dendrites (Riederer et al., 1986), the cell bodies and dendrites contain neurofilaments composed primarily of the 145 and $68 \mathrm{kDa}$ polypeptides, while the cross- bridging $200 \mathrm{kDa}$ polypeptide is present primarily in axons in association with the 145 and $68 \mathrm{kDa}$ polypeptides (Hirokawa et al., 1984). Therefore, while there is a temporal relationship between the expression of neurofilament polypeptides and spectrin subtypes, the compartmentation is reversed. This suggests that the interaction of brain $\operatorname{spectrin}(240 / 235 \mathrm{E})$ to neurofilaments in the dendrites observed by immunoelectron microscopy (Zagon et al., 1986) may be through association with the 145$68 \mathrm{kDa}$ neurofilament core; this is probably also the case for brain spectrin(240/235) in the axons, as the $200 \mathrm{kDa}$ axonal neurofilament polypeptide is not expressed until a later development stage.

The larger component of microtubule-associated protein 2, MAP2a, is expressed similarly to brain spectrin(240/235E), appearing at postnatal day 10 of rat brain development (Binder et al., 1984; Burgoyne and Cumming, 1984; Riederer and Matus, 1985). The colocalization of MAP2a and brain spectrin(240/ $235 \mathrm{E}$ ) in neuronal dendrites and the association of brain spec$\operatorname{trin}(240 / 235 \mathrm{E})$ to dendritic microtubules (Zagon et al., 1986) suggest that MAP2a could play a role in the attachment of this spectrin subtype to microtubules during the establishment of the dendritic compartments. It may be relevant that coprecipitation of MAP2, actin, and neurofilaments with fodrin (brain spectrin) antibody from rat cerebral cortex preparations has been described in a preliminary report (Siman and Lynch, 1985).

In the rbc, spectrin is associated with the cytoplasmic surface of the plasma membrane through an interaction with the peripheral membrane phosphoprotein termed ankyrin (for review, scc Bennett, 1985). Mammalian brain contains an analog of the spectrin binding protein ankyrin, which may be essential for linking spectrin subtypes to membranes (Davis and Bennett, 1984). However, it is not yet known whether mammalian neurons, like avian neurons (Nelson and Lazarides, 1984), contain 2 distinct ankyrin subtypes which are coexpressed with the brain spectrin subtypes.

\section{Relationship between the expression of brain spectrin subtypes during mammalian and avian brain development}

The developing chicken brain also contains 2 forms of brain spectrin. Chicken brain spectrin(240/235) is expressed constitutively in all neuronal cell bodies and processes during all stages of cerebellar morphogenesis (Lazarides and Nelson, 1983b). Therefore, its expression is temporally similar to mammalian brain spectrin(240/235), although spatially the avian spectrin subtype has been reported to be found in neuronal cell bodies, dendrites, and axons (Lazarides and Nelson, 1983a), while the mammalian spectrin subtype is found in adult neuronal axons (Riederer et al., 1986; Zagon et al., 1986; this report).

The erythrocyte-related form of chicken brain spectrin [brain spectrin(240/230) or (240/220)] has been suggested to accumulate exclusively at the plasma membrane of neuronal cell bodies and dendrites at the stage at which axosomatic contacts are established (Lazarides and Nelson, 1983b). Therefore, chicken brain spectrin(240/230) expression is both temporally and spatially related to mammalian brain $\operatorname{spectrin}(240 / 235 \mathrm{E})$, although these proteins are structurally distinct. Mammalian brain $\operatorname{spectrin}(240 / 235 \mathrm{E})$ is also associated with the cytoplasmic surface of organelle membranes in addition to the plasma membrane (Zagon et al., 1986), while avian brain spectrin(240/230) has been suggested to be exclusively associated with the plasma membrane (Lazarides and Nelson, 1983a). 


\section{Significance of brain spectrin subtype expression}

Although this is the first report of spectrin subtype expression during mammalian brain development, Sobel and Alliegro (1985) have found a $240 \mathrm{kDa}$ polypeptide that cross-reacts with antibody to avian erythrocyte $\alpha$-spectrin in mouse embryo, as early as the 2-cell stage. Given the present observations showing a spectrin subtype in germinal cells of the mouse brain, it would appear that spectrin may be expressed in all developing cells and tissues. The role of spectrin during embryogenesis is unknown, although functions such as maintenance of membrane architecture, cell shape, and organelle and vesicle translocation attributed to spectrin in adult systems (Goodman and Zagon, 1984, 1986) may be involved. Recently, Zagon et al. (1986) have examined spectrin subtypes in adult mouse brain with immunoelectron microscopy. Spectrin was found not only in association with the cell membrane, but formed an interconnecting network between cellular organelles. It is interesting to speculate that spectrin may be an important element linking the structural components of developing cells.

\section{References}

Altman, J. (1972a) Postnatal development of the cerebellar cortex in the rat. II. Phases in the maturation of purkinje cells and of the molecular layer. J. Comp. Neurol. 145: 399-464.

Altman, J. (1972b) Postnatal development of the cerebellar cortex in the rat. III. Maturation of the components of the granular layer. J. Comp. Neurol. 145: 465-514.

Bennett, V. (1985) The membrane skeleton of human erythrocytes and its implication for more complex cells. Annu. Rev. Biochem. 54: 273-304.

Bennett, V., J. Davis, and W. E. Fowler (1982) Brain spectrin, a membrane-associated protein related in structure and function to erythrocyte spectrin. Nature 299: 126-131.

Binder, L. I., A. Frankfurter, H. Kim, A. Caceres, M. R. Payne, and L. I. Rebhuhn (1984) Heterogeneity of microtubule-associated protein 2 during rat brain development. Proc. Natl. Acad. Sci. USA 81:56135617.

Burgoyne, R. D., and R. Cumming (1984) Ontogeny of microtubuleassociated protein 2 in rat cerebellum. Differential expression of the doublet polypeptides. Neuroscience 11: 157-167.

Burridge, K., T. Kelly, and P. Mangeat (1982) Nonerythrocyte spectrins: Actin-membrane attachment proteins occurring in many cell types. J. Cell Biol. 95: 478-486.

Davis, J. Q., and V. Bennett (1984) Brain ankyrin. A membrane associated protein with binding sites for spectrin, tubulin and the cytoplasmic domain of the erythrocyte anion channel. J. Biol. Chem. 259: $13550-13559$.

Glenney, J. R., J. P. Glenney, and K. Weber (1982) Erythroid spectrin. brain fodrin, and intestinal brush border proteins (TW 260/240) are related molecules containing a common calmodulin-binding subunit bound to a variant cell type-specific subunit. Proc. Natl. Acad. Sci. USA 79: 4002-4005.
Goodman, S. R., and I. S. Zagon (1984) Brain spectrin: A review. Brain Res. Bull. 13: 813-832.

Goodman, S. R., and I. S. Zagon (1986) The neural cell spectrin skeleton: A review. Am. J. Physiol. 250: C347-C360.

Goodman, S. R., I. S. Zagon, and R. R. Kulikowski (1981) Identification of a spectrin-like protein in nonerythroid cells. Proc. Natl. Acad. Sci. USA 78: 7570-7574.

Goodman, S. R., B. M. Riederer, and I. S. Zagon (1986a) Spectrin subtypes in mammalian brain. BioEssay $5: 25-29$.

Goodman, S. R., I. S. Zagon, D. B. Coleman, and P. J. McLaughlin (1986b) Spectrin expression in neuroblastoma cells. Brain Res. Bull. 16: 597-602.

Hirokawa, N., M. A. Glicksman, and M. Willard (1984) Organization of mammalian neurofilament polypeptides within the neuronal cytoskeleton. J. Cell Biol. 98: 1523-1536.

Laemmli, U. K. (1970) Cleavage of structural proteins during the assembly of the head of bacteriophage T4. Nature 226: 680-685.

Lazarides, E., and W. J. Nelson (1983a) Erythrocyte and brain forms of spectrin in cerebellum: Distinct membrane-cytoskeletal domains in ncurons. Science 220: 1295-1296.

Lazarides, E., and W. J. Nelson (1983b) Erythrocyte form of spectrin in cerebellum: Appearance at a specific stage in the terminal differentiation of neurons. Science 222: 931-933.

Lowry, O. H., N. J. Rosebrough, H. L. Farr, and R. J. Randall (1951) Protein measurement with the folin phenol reagent. J. Biol. Chem. 193: 265-275.

Nelson, W. J., and E. Lazarides (1984) The patterns of expression of two ankyrin isoforms demonstrate distinct steps in the assembly of the membrane skeleton in neural morphogenesis. Cell 39: 309-320.

Repasky, E. A., B. L. Granger, and E. Lazarides (1982) Widespread occurrence of avian spectrin in nonerythroid cells. Cell 29: 821-833.

Riederer, B., and A. Matus (1985) Differential expression of distinct microtubule-associated proteins during brain development. Proc. Natl. $\Lambda$ cad. Sci. USA 82: 6006-6009.

Riederer, B. M., I. S. Zagon, and S. R. Goodman (1986) Brain spectrin $(240 / 235)$ and brain spectrin (240/235E): Two distinct spectrin subtypes with different locations within mammalian neural cells. J. Cell Biol. 102: 2088-2097.

Schmitt, H., I. Gozes, and U. Z. Littauer (1977) Decrease in levels and rates of synthesis of tubulin and actin in developing rat brain. Brain Res. 121: 327-342.

Shaw, G., and K. Weber (1982) Differential expression of neurofilament triplet proteins in brain development. Nature 298: 277-279.

Siman, R., and G. Lynch (1985) Fodrin binds neurofilament and actin in rat brain subcellular fraction. J. Neurochem. (Suppl.) 44.

Sobel, J. S., and M. A. Alliegro (1985) Changes in the distribution of a spectrin-like protein during development of the preimplantation mouse embryo. J. Cell Biol. 100: 333-336.

Zagon, I. S., and P. J. McLaughlin (1978) Perinatal methadone exposure and its influence on the behavioral ontogeny of rats. Pharmacol. Biochem. Behav. 9: 665-672.

Zagon, I. S., P. J. McLaughlin, and S. R. Goodman (1984) Localization of spectrin in mammalian brain. J. Neurosci. 4: 3089-3100.

Zagon, I. S., R. Higbee, B. M. Riederer, and S. R. Goodman (1986) Spectrin subtypes in mammalian brain: An immunoelectron microscopic study. J. Neurosci. 6: 2977-2986. 